\title{
A New Attraction Model For Evaluating The Effectiveness Of Selling Effort
}

Joseph M. Spiteri, (E-mail: jspiteri@marketdynamics.com), President, Market Dynamics, Inc. William C Johnson, (E-mail: billyboy@huizenga.nova.edu), Nova Southeastern University

\begin{abstract}
Deployment analysis evaluates the allocation of selling effort directed towards achieving the firm's sales objectives. While recent improvements in salesforce automation have resulted in more optimal levels of sales call effort, managerial judgments are still crucial to effectively deploy a salesforce. Moreover, the availability of large databases of target profiles, especially in consumer markets and some business markets like pharmaceuticals, has led to better targeting of accounts. Nevertheless, a robust model is still needed to post-hoc analyze the effectiveness of all these efforts. An analytical framework, based on the user-friendly Portfolio Model, has been found to provide more accurate diagnostic insights when the ideal "perfect-knowledge" benchmark is used as a comparison. The difference in this approach, which this paper calls the Attraction Model, is in the treatment of the variables. They have been operationalized to take advantage of "perfectknowledge" in market shares, growth rates and account usage patterns obtained from a large random sample. In this way the frequency of sales calls, as a measure of the sales deployment efforts, can be scrutinized and the level of success evaluated when compared to the ideal effort. Strategic corrections can then be made for the next promotional period.
\end{abstract}

\section{Introduction}

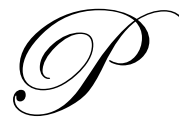

ersonal selling is a critical element in relationship marketing and one of the firm's resources with the potential of sustaining a competitive advantage. This paper is concerned with the post-hoc analysis of salesforce effort or workload after all the deployment decisions have been made. As territorial workload has been shown to have a critical impact on performance, there are four important aspects of salesforce deployment that impact this workload: salesforce sizing, sales person's locations, sales territory alignment, and sales resource allocation to heterogeneous accounts. A great deal of research has been conducted on all four deploymentareas so that optimizing the productivity of the salesforce has reached high academic and practitioner levels of knowledge (Hess and Samuels 1971, Easingwood 1973, Lodish 1975, Heschel 1977, Segal and Weinberger 1977, Richardson 1979, Zoltners and Sinha 1983, Skiera and Albers 1996). However, after all the sales deployment decisions have been made and implemented, this key decision still remains: "How effective is (was) the selling effort allocation to specific accounts?"

\section{Background}

The focus on salesforce productivity is essential as more than $\$ 500$ billion a year are spent by American companies (Zoltners 1999). Heide (1998-1999) reports that the cost of an industrial sale call is now \$200 per call. Moreover, accounts are becoming more restrictive of the time spent with sales persons. Accordingly, even modest improvements in the account coverage by a salesforce can make a significant contribution to the firm's bottom line (Zoltners and Lorimer 2000). While the monitoring of call frequencies is now commonplace for many salesforces, the accurate recording and the reliance on this reporting for many firms are still problematical issues. Moreover, with a few exceptions, the availability of market shares for every product purchased by an account is seldom available. Consequently, during a promotional period salesforce management is often unsure, even unaware, as to

Readers with comments or questions are encouraged to contact the authors via email. 
how effectively the sales call strategies have been implemented. Under these circumstances, a marketing oriented top management team is wise in making use of a marketing audit process to independently check on the appropriate levels of call frequencies and on the effectiveness of the account targeting. An account allocation analytical tool presented in this paper provides a robust method to analyze these efforts. While this tool can be used at any time during a promotional cycle, it is highly recommended at its end. This paper illustrates an example of how this tool is applied to a large firm in the veterinary pharmaceutical industry. The analysis can be viewed as a final "20/20 hindsight" or retrospective look at the implementation of the strategies and hence the final score card of the targeting effort and its performance. This new analytical tool is based on the work of LaForge et al (1985) and their portfolio model.

\section{Portfolio Models}

LaForge, Cravens and Young (1985) introduced the portfolio model as an analytical tool to "help management to deploy its salesforce more productively." It was cost-effective, user-friendly and these researchers offered examples of how and when it worked. The portfolio model is positioned as a more acceptable compromise to the alternatives of the simplified approach and the decision models approach.

The simplified approach typically consists of procedures for classifying accounts' market potential and setting sales call coverage guidelines in, typically, four account classifications, the A, B, C, and D categories. LaForge et al (1985) notes that this approach is easy to develop and use, but it is incomplete and that it is often unrealistic to assume that all accounts in the same market potential category should receive the same number of sales calls.

The decision models approach is acknowledged as being more advanced than the simplified approach. For example, CALLPLAN uses mathematical algorithms to search for optimal call frequencies for each account based $n$ the calibrated relationships of sales calls to account sales (Lodish 1971). However, LaForge et al (1985) acknowledge that this approach requires substantial time, a wide range of objective data and significant expenditures. Moreover, many managers still do not understand decision models and the model's complexity makes it difficult to get salespersons buy-in and use.

LaForge et al (1985) advanced the portfolio model as a middle ground that is more theoretically desirable than the simplified approach, which managers also found easier to understand and use than decision models. Essentially, the portfolio model defines two axes: account opportunity and strength of position. As shown in Figure 1, a demarcation value - the midpoint, median or some other value - is then used to form the quadrant of segments, called Attractiveness Segments. Every position in these segments reflects the underlying normative rule for resource allocation, which is that scarce resources should be allocated to competing units according to their attractiveness. In the portfolio model, "attractiveness" is a notion that has two components:

\subsection{Account Opportunity}

An evaluation of an account's need for and ability to purchase the Company's product, in this case veterinary pharmaceuticals. Factors that influence account opportunity include, but are not limited to: the size of the account, its growth rate, socio-economic location, financial ability to purchase, and other situational factors such as willingness to allow sales visits and the required level of service.

\subsection{Strength of Position}

An evaluation of any competitive advantages or distinct competencies the particular sales organization or sales person enjoys with the account. Factors that influence strength of position include any advantages the firm might have, or could tactically or strategically develop or acquire, with an account. These might include detailed knowledge of account operations, relationship with an account, or any other factor related to an increased probability of the account purchasing the firm's brand rather than competing brands. 
LaForge et al (1985) operationalized the above two variables from composites of the ratings obtained from a sales person administered questionnaire. The questionnaire consists of 5-point Likert scaled questions, ranging from "Strongly disagree" to "Strongly agree" which are administered to the sales people to provide interval ratings on all their accounts. Examples of the questions asked are: (1) This account's business has a high growth rate; (2) I am familiar with the account's business; and (3) This account has good attitude toward our brand and equipment. The combined ratings from the answers to these questions are then used as $\mathrm{X}-\mathrm{Y}$ coordinates to define the four attraction segments depicted below. Various operationalization options are available showing the adaptability of the approach. Figure 1 depicts the above approach for the general portfolio model.

Figure 1: General Portfolio Model

\begin{tabular}{|c|c|c|}
\hline & \multicolumn{2}{|c|}{ Strength of Position } \\
\hline & Strong & Weak \\
\hline $\begin{array}{l}50 \\
0.00 \\
=\end{array}$ & \begin{tabular}{|c|} 
Attractiveness Segment 1: \\
High Account Opportunity and Strong Strength \\
of Position
\end{tabular} & \begin{tabular}{|c|} 
Attractiveness Segment 2: \\
High Account Opportunity but Weak Strength of \\
Position
\end{tabular} \\
\hline 莽 & \begin{tabular}{|c|} 
Attractiveness Segment 3: \\
Low Account Opportunity and Strong Strength of \\
Position
\end{tabular} & \begin{tabular}{|c|} 
Attractiveness Segment 4: \\
Low Account Opportunity and weak Strength of \\
Position
\end{tabular} \\
\hline
\end{tabular}

While the portfolio model can be in a few circumstances a viable and even valuable approach, some constructive criticism of the methodology is warranted. In the portfolio model, the answers to the interval-scaled questionnaires are combined additively to provide the $\mathrm{X}-\mathrm{Y}$ values for the two axes. The questions that arise are: "How valid is the equal interval assumption?" "How theoretically justified is the additions of the ratings?" and "Is the assumption of no interaction between the items valid?" Just looking at the two questions on the questionnaire above ("high growth rate" and "strong financial position of the account") makes one suspicious of an interaction or collinearity effects. Moreover, even after these scales are obtained there is still another analytical decision to be made: "How are scale values going to be used to obtain the attraction segments?" Using the scales in a linear (X-Y coordinates), as will be shown later, and not in some other way, say in a multiplicative combination, assumes that every account is considered as a viable sales call target. However, given the need to customize the axes to align with both the purpose of the analyses and the strategic objective of the sales effort, the linear combination will not always capture the goals of the firm's strategy and hence will not represent the phenomena as well. Moreover, the portfolio model does not make use of the firm's salesforce subjective-judgmental based ABCD categorization, and the organizational learning that the categories incorporate. As will be shown later the attraction model uses these classifications and hence derives more relevant insights. Nevertheless, the attraction model is based on the valuable contribution made by LaForge et al (1985).

\section{An Attraction Model of Accounts}

The portfolio model defines the four specific attractiveness segments, but also indirectly advances the more general notion of "attraction" or "attractiveness" of accounts. Attraction has its foundation in the principle that for any market exchange, the motivation for that exchange is motivate by the mutual benefits derived from the encounter. Just as there is an attraction to the brand (product or service) by the consumer or client, there is also an attraction of the consumer or client to the firm. This mutual attraction is at the core of the marketing concept. Clearly, the attraction of consumer to the brand is a function of the marketing mix, but the attraction of the consumer to the firm can also be thought of as a function of what might be called the "attraction mix." Two independent variables of this mix have been defined by the portfolio model in the context of the "account opportunity" and "strength of position." As pointed out above, the "attraction mix" consists of several account opportunity variables (size of account, its growth rate, socio-economic location, financial ability to purchase, and other situational factors) and strength of positions variables (company or product loyalty, the accounts special relationships with salesperson, 
previous experience with products and so on). These are the profile characteristics of accounts that are clearly desirable from the perspective of the firm.

The need to combine or to derive a mathematical functional relationship for some or all of the above variables, may be accomplished with a simple linear (as in the portfolio model), but due to the potential interactions of the many variables a more theoretically desirable functions, such as multiplicative or exponential relationships, might be more appropriate. Hence the attraction model is more of a general approach and easily handles the additive approach of the portfolio model as a special case. The attraction model is also different from the decision models, in that the latter is primarily a tool for a priori use but the attraction model is for a posteriori evaluation of sales call effort. For a salesforce that uses decision models a post-hoc evaluation tool may not be as crucial provided proof of the model's effectiveness leads to a committed use by the sales force. However, if management needs an independent corroborative audit that even decision models are being effectively used then a post-hoc evaluation using the attraction model would also be warranted.

The notion of "attractiveness" parallels a similar definition by Bell, Kenny and Little ("BKL", 1975). BKL's work is on the attraction of brands to consumers as a result of marketing mix activities of a firm. BKL also state that when making a purchase decision, consumers choose one brand from a set of alternative brands available in the market. These authors posit that the only determinant of market shares is the "attraction" consumers feel toward each alternative brand. They state that:

"Attraction may be a function of the seller's advertising expenditure and effectiveness, the price of his product, reputation of the company, the service given during and after purchase, location of retail stores, and much more" (p.137).

The definition of "attraction" when applied to accounts is also implied in the previous definitions of the two axes of account opportunity and strength of position. Therefore, the attraction a firm feels towards each account may be defined as follows:

"Attraction may be a function of the buyer's size and growth rate, location, long term value and financial viability, attitudes towards firms and sales people, and much more."

The work of BKL goes on to define axioms that are appropriate for treating the success of a brands attraction in terms of a share of a proportion of the sum of all the attraction values. The extension of BKL's work to apply to the attraction of accounts is a fruitful area for future research. Moreover, in order to see how the present attraction model is used to empirically test its application, this paper now reports on an analysis of a leading firm in the veterinary pharmaceutical industry in the following case history.

\section{Company Case History}

Bonoma (1985) observes that insights gained through case research can be useful for expanding our salesforce knowledge base. This is one of the reasons for examining the case history and analysis in this paper as it uses this case to inductively generalize a model that will apply to other firms. The analyzed company, DogCare Inc, is a leader in the US veterinary pharmaceutical market. Unlike the human pharmaceutical market, which has the extensive monitoring of physician scripts at the clinic level, the veterinary pharmaceutical market does not a have a database that tracks treatments at every clinic - often called "brick data". However, there is a syndicated service providing monthly tracking of selected high-volume products using a large randomly selected panel of small animal clinics. The data from this independently compiled market shares and usage volume is used to perform the post-hoc analyses of sales call frequency deployment. This is what this paper calls the "perfect-knowledge" benchmark. It is used as the ideal to compare with the executed sales call strategy.

The case history details of the analyzed firm's competitive position are needed to underscore the wisdom of the sales call strategy. This is also very important in choosing the way the two axes in the model are operationalized and it has a significant influence, as will be illustrated later, on the placement of the ABCD categorized clinics into 
the four attractiveness segments. The company evaluated is a business-to-business firm that has a large salesforce of 160 people (20-25\% larger than their next biggest competitor). The firm markets veterinary pharmaceuticals in a medicinal category.

In this situation, like many other similar business-to-business markets, the salesforce is the largest component of the marketing mix, even though a small amount of print advertising and price promotion are used to support the salesforce effort. There is no direct-to-consumer TV advertising for this category. The setting is essentially a stable market for a veterinary diagnosis, with highly recommended treatment, and with essentially two key competitors. It is therefore zero-sum games as both companies are beyond the break-even positions and any favorable outcomes are directly related to their market share position. There is very little growth in the market, and growth potential is also at a near maximum. Moreover, the two major product groups are only slightly, and not significantly, differentiated. This means that more depends on the success of the implementation of the promotional marketing mix elements and, for our analyses, superior implementation of a call frequency sales strategy.

The analyzed-firm, designated as DogCare for reasons of confidentiality, had the first-mover advantage in the category with a brand that has the convenience of monthly dosing. The older firm, CanineProducts, has the inconvenient daily dosing and over the years steadily lost market share. For many years DogCare had been a leader, not only in the category but also in the industry, as it established a strong brand and company franchise. However, after the introduction of BestFriend's competitor product in 1991, DogCare saw its market share steadily decline as shown in the following table:

Table 1: Market Shares of Revenues 1991-1998

\begin{tabular}{||l|c|c|c|c|c|c|c|c|c||}
\hline \hline COMPANY & 1991 & 1992 & 1993 & 1994 & 1995 & 1996 & 1997 & 1998 & 1999 \\
\hline DogCare & $62 \%$ & $57 \%$ & $56 \%$ & $54 \%$ & $53 \%$ & $52 \%$ & $50 \%$ & $42 \%$ & $42 \%$ \\
\hline BestFriend & $17 \%$ & $26 \%$ & $30 \%$ & $34 \%$ & $36 \%$ & $41 \%$ & $44 \%$ & $53 \%$ & $52 \%$ \\
\hline CanineProducts & $21 \%$ & $17 \%$ & $14 \%$ & $12 \%$ & $11 \%$ & $7 \%$ & $6 \%$ & $5 \%$ & $6 \%$ \\
\hline TOTAL & $100 \%$ & $100 \%$ & $100 \%$ & $100 \%$ & $100 \%$ & $100 \%$ & $100 \%$ & $100 \%$ & $100 \%$ \\
\hline
\end{tabular}

BestFriend launched its initial product in early 1991 with a slightly improved therapeutic claim (more parasitic coverage) over the product from DogCare with a similar monthly dosing. This claim of covering more (albeit a minor parasite) had a slight therapeutic advantage, but BestFriend had a smaller salesforce and was not established either in the product category or in the industry. One year after launch BestFriend had taken market share from both DogCare and CanineProducts and over the ensuing years, BestFriend had gained a market share of approximately 53\% at its peak. BestFriend then launched its second product late in 1997 that offered more therapeutic flexibility. By that time, CanineProducts ceased to be a force and it was left to DogCare to ward off this new threat with essentially the advantage of its salesforce and its reputation in the industry. DogCare's strategy from the very beginning was to protect their key accounts.

Both DogCare's and BestFriend's salesforce strategies rely on the segmentation of customers and prospects based on a ranking of their customer potential into A, B, C or D categories. In the absence of the availability of objectively measured potential for all customers, these ratings are often based on the experience of the salesforce and management. Some of these sales people have had more than 15 years in the same territory and are very knowledgeable about a wide range of aspects in their accounts. While some measures are sparingly available, such as number of pets in a zip code, the size of the practice and the socioeconomic service area, these are only reliable to define sales territories. Many veterinary practices share these emporographics and, ultimately, salesforce judgments, intuition and tacit knowledge are the primary means available when objective, individual demand curves are not available.

The different ratings (A, B, C, or D) dictate how frequently the salesperson visits the client, what sales promotion devices are used and even what price to charge, often in the form of free goods or delayed payment schedules. The rating scheme, therefore, has a direct bearing on the way the marketing mix is varied to each segment, with the expectation that differential customer behavior might result from the differentiated marketing mix 
stimuli. For example, in the veterinary pharmaceutical industry for a promotional period of one year, a leading firm uses a call frequency of 12 clinic visits for all A accounts, eight for B accounts, six for C, and one for D accounts. These call levels are derived after many interrelated salesforce deployment decisions, such as the number of salespeople, their organization into territories and assignments of the products to sell (Lodish, 1974 and 1975). Moreover, the salesforce budget restricts and company policy punishes non-compliance of the call frequency strategy. However, the reality of the freedom enjoyed by sales people often presents ample opportunity for unsupervised, and hence undetected, deviations from the stated strategies, which explains why management is generally concerned with salesforce control and evaluation issues.

From the above, a case can be made that DogCare's salesforce constitutes its competitive advantage and that DogCare places significant weight on the success of its salesforce effort. Accordingly, since the salesforce effectiveness is highly dependent on its efficient deployment, some post-hoc analyses of its success is warranted and is normatively recommended after every promotional period. The strategy pursued by DogCare is "protect all the accounts" in the priority of size of account and any accounts with brand switching opportunity. Accordingly, the ABCD category, in DogCare's case, is not based on market potential as in LaForge et al (1985) examples. These categories were a reflection or implementation of the sales strategy and were selected with the objective of protecting all of DogCare's key accounts. To obtain these categorization, DogCare asked all its representatives and sales force management based on their years of experience to select $7 \%$ of all accounts as A accounts, which are largest and best accounts that DogCare wants to protect to be called on 12 times a year. Then these were followed by $46 \%$ of all accounts as B accounts to be called on eight times and then $43 \% \mathrm{C}$ accounts for six times a year calling. The remainder of $4 \%$ is D accounts to be called on once a year. As the salesforce selected each account the question they kept in mind was "Which accounts do I want to protect in my territory?" To analyze if they succeeded in this strategy the "perfect-knowledge" benchmark methodology is used.

\section{Perfect-Knowledge Benchmark Methodology}

Unlike the portfolio model, the attraction model incorporates the implemented elements of the simplified approach, by morphing the $\mathrm{ABCD}$ categories into the portfolio framework in the exact proportion that the sales strategy assigned the accounts. In this way DogCare's implemented sales strategy is reflected in the model and is being set up for comparison to the "perfect-knowledge" scenario. For example, in Table 2, the ABCD accounts of the analyzed firm are distributed into the four attraction segments. All $35 \mathrm{~A}$ accounts are in attractiveness segment 1 , the 219 B accounts are in segment 2 and the 202 C's are in Segment 3. The very few D accounts are in segment 4. The paper calls this the "aligned scenario" as the ABCD categorization system reflects the analyzed firm's best knowledge about how the call frequencies should be distributed.

\section{Table 2: ABCD Accounts Morphed into Portfolio Model}

\begin{tabular}{|c|c|c|c|c|c||}
\hline Class Categories & \multicolumn{6}{|c|}{ Attraction Segments } & \multirow{2}{*}{ Total Accounts } \\
\cline { 2 - 5 } & 1 & 2 & 3 & 4 & \\
\hline A & 35 & & & & 35 \\
\hline B & & 219 & & & 219 \\
\hline C & & & 202 & & 202 \\
\hline D & & & & 15 & 15 \\
\hline Totals & 35 & 219 & 202 & 15 & 471 \\
\hline
\end{tabular}

The analyses of the call frequencies defined by the firm's implemented deployment strategy have been given earlier and these will subsequently be compared to the perfect-knowledge scenario. The perfect-knowledge scenario makes use of the sample-obtained actual consumption (by canine patients) values of the product groups (and growth rate multiplier, if available) to define the account opportunity axis, and the analyzed firm's product group market share to define the strength of position axis. Both these values come from panel survey methodology of monthly tracking of a randomly selected set of accounts. The consumption values for the analyzed firm have 
been validated to $1 \%$ of the firm's actual shipments and so the perfect-knowledge scenario may not be totally perfect but is very reliable.

The account opportunity axis uses the values for consumption or treatments per month, and the strength of position axis is based on the market share of DogCare's brands in each of the accounts. These values are the independent variables or scales used for the depiction of the model seen in Figure 2. As can be seen from the overlapping ranges, the quadrants by design are no longer symmetrical as in the general portfolio model. The difference is created by a non-linear "combination of the two axes or measures." While the general portfolio model defines them in mutually exclusive segments using X-Y coordinates, the attraction model multiplies the values of the axes to get a single value, which is then used to position the account in the attractiveness segments in the same exact proportion as the sales strategy or the aligned case detailed earlier. The three scenarios-strategy, aligned and perfect-knowledge - are now ready for comparison.

Figure 2: Perfect Knowledge Benchmark Model

\begin{tabular}{c}
\multicolumn{2}{c|}{$\begin{array}{c}\text { Market Share of DogCare Brand as Strength of Position } \\
\text { Strong }\end{array}$} \\
\cline { 2 - 3 }
\end{tabular}

A review of the data set in Appendix A will make the computational differences between the portfolio and attraction methodologies clearer. As illustrated in an example of Appendix A, the columns are as shown: (1) Clinic is the number identifier; (2) Sum of Total is the treatments per month for that clinic; (3) Account Opportunity is the rating given based on the Sum of Total figure; (4) Strength of Position is the rating given on the bases of Share of Company; (5) Portfolio Mid Segment is the attraction segment assignment based on the rating for Account Opportunity and Strength of Position in relation to the midpoint of the scale; (6) Share of DogCare is the proportion of the brands for DogCare in each clinic; (7) Attraction Model Perfect Knowledge is based on the multiplication of Sum of Total and Share of DogCare to Accounts Share; (8) Sum of DogCare is Sum of Total times Share of DogCare; (9) Accounts Share of DogCare is the Sum of DogCare as a proportion of the total of DogCare; (10) Class DogCare is the ABCD categorization; (11) Calls is the appropriate number of calls for that category; (12) Aligned is the attraction segment assignments based on the Class of DogCare categories, (13) Misclassified Accounts is the comparison of the a priori ABCD categories when compared to the a posteriori Attraction Segment classification, with the "U" predicting a decrease from under-coverage, while a "C" designates correct coverage, and "O" designates over-coverage with the expected increase in market shares.

The following examples illustrate the key mathematical difference between the portfolio model and the attraction model. For clinic 23853 the Account Opportunity is a 1 and Strength of Position is a 1, the Portfolio Midpoint value would position this X-Y $(1,1)$ into attractiveness segment 1 , whereas if for clinic 6947 the Account Opportunity is a 2 and Strength of Position is a 1, the Portfolio Midpoint would place this in attractiveness segment 3. However, the value for Attraction Model Perfect Knowledge for these clinics would place clinic 23853 in the same segment 1 attractiveness but place clinic 6947 into attractiveness segment 2 not 3 because the Account Share 
of DogCare is higher than it is for clinics in segment 3. The methodology for the positioning of the other clinics is similar to the above.

The rationale for the multiplication of the axes is as follows. As DogCare's sales strategy is fundamentally defensive - to protect all the current key accounts - and is not focused on regaining lost accounts. (DogCare would welcome regaining lost accounts as a byproduct of sales calls, but it recognizes that the salesforce resource cannot regain or maintain accounts equally well and so has chosen to prioritize protecting possible losses of more key accounts). Hence, for a defensive strategy the attraction function is more appropriately obtained by the accounts total DogCare product consumption multiplied by DogCare's brand market share. On the other hand, for example, an attacking strategy could define the attraction of accounts by consumption multiplied by the share of BestFriend's products. After the most appropriate operationalization of the attraction of accounts is performed, the attraction segments are then assigned to the variable "Accounts Share of DogCare" in the same proportion as the sales call strategy, that is 35 get the top 35 "Attraction Model Perfect-Knowledge" assignments, followed by the 219 next most important accounts and so on.

In essence, this is also the consumption of DogCare's brand as measured by monthly treatments. While this may approximate DogCare's sales to the accounts or the account's purchases of DogCare's brand, this is not the same as the brand's consumption. An account's brand purchases do not equate with consumption as usage rates (by veterinary clinics) determine consumption, while purchases can be influenced by inventory or stocking levels. Moreover, this is what the sales strategy had in mind as the following comparison in Table 3 shows: 14 out of the 35 A-accounts in Segment 1, 131 of 219 B accounts in Segment 2 and so on. Using the general portfolio model (see Table 4) does not provide as much congruence to the sales strategy as is seen in Table 3; only 12 of the A accounts, 88 of the B accounts and so on are in the right segments.

Table 3: Distribution of ABCD Using Multiplication of Axes Values (Attraction Model)

\begin{tabular}{||c|c|c|c|c|c||}
\hline & \multicolumn{4}{|c|}{ Attraction Segments } & Total \\
\hline & 1 & 2 & 3 & 4 & \\
\hline A & 14 & 11 & 10 & & 35 \\
\hline B & 20 & 131 & 64 & 4 & 219 \\
\hline C & 1 & 76 & 115 & 10 & 202 \\
\hline D & & 1 & 13 & 1 & 15 \\
\hline Total & 35 & 219 & 202 & 15 & 471 \\
\hline
\end{tabular}

If the approach of the portfolio model is used on the data of the firms case history, the dispersion of the ABCD accounts are shown in Table 4. The model assumes that the $\mathrm{ABCD}$ categorization reflect a firm's categorization of the "market potential" but is incomplete (LaForge et al 1985). This suggests that it can only be accommodated as the account opportunity axis since it clearly has to be one of the axes and it does not make any sense as the strength of position axis (this would more appropriately be termed "brand potential" and not "market potential"). If the ABCD categories are used as account potential, when combined as $\mathrm{Y}$-values with the available $\mathrm{X}$-axis and market shares, the attractiveness segments have the dispersion shown in Table 4. By comparison the amount of congruence of the ABCD categories in the two sets of attraction segments it is clear that Table 3 is less dispersed and therefore superior than Table 4, which has more misclassification of accounts dispersed in several segments. As will be discussed later, there is, therefore, more over-and-under coverage and leads to lower call averages as shown in Table 6 when compared to Table 5.

Of course this analysis is not asserting that the portfolio model is not sometimes a valid approach. However, for use as a planning tool, the midpoint definition of the axes and subsequent attraction segments assumes that the whole market should be the target for sales calls and that the sales effort should be evenly distributed. If this were congruent with any particular sales strategy, the mid-point definition would apply. However, in a promotional period most sales call strategies target a focused segment, such as DogCare's strategy of retaining all of its most important accounts. Other focused strategies examples are the penetrating of more major accounts or getting more sales from existing accounts or brand switching from competitive accounts. The sales strategy rarely targets every account available, unless the firm was launching a new product. To be successful in marketing in these days of competitive markets, marketing and sales strategies must recognize the need for market segmentation. As Sinha and Zoltners (2001) observe from dealing with over 300 salesforce alignment assignments, "focus strategies dominate scattered strategies." 
Table 4: Dispersion of ABCD Using X-Y Coordinates the Axes Values (Portfolio Model)

\begin{tabular}{|c|c|c|c|c|c|}
\hline & \multicolumn{4}{|c|}{$\begin{array}{l}\text { Attraction } \\
\text { Segments }\end{array}$} & \multirow[t]{2}{*}{ "Total } \\
\hline & 1 & 2 & 3 & 4 & \\
\hline $\mathrm{A}$ & 12 & 9 & 11 & 3 & 35 \\
\hline B & 59 & 88 & 47 & 25 & 219 \\
\hline $\mathrm{C}$ & 15 & 45 & 87 & 55 & 202 \\
\hline D & & 6 & 4 & 5 & 15 \\
\hline Total & 86 & 148 & 149 & 88 & 471 \\
\hline
\end{tabular}

Although the segments are no longer actually symmetrical as depicted in Figure 2, for communication purposes to management or sales persons, the four quadrants may remain as shown. However, the real relationship is depicted in Figure 3 and 4. Figure 3 shows the dispersion of accounts when the two values on the attraction axes are used as X-Y coordinates. This scatter diagram shows the dispersion of values concentrated around the extremes, with many cases where DogCare's brand has 100\% market share across any value of account opportunity and many cases where it is zero at even high account opportunity values. When the attractiveness segments are defined in terms of the multiplication of the two axes the dispersion of the accounts are as shown in Figure 4. Note the large dispersion for the A-accounts in Segment 1. However, the dispersion values are a function of the account market shares and it is easy to read the insights from this approach when compared to Figure 3.

Figure 3: Scatter Diagram of Accounts

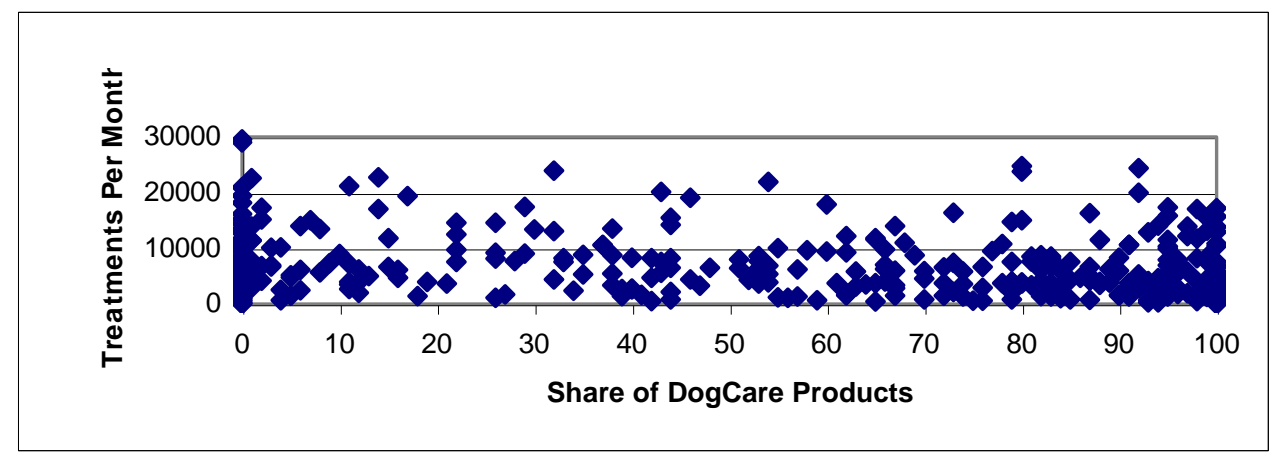

Figure 4: Attractiveness Segments of Accounts using Market Share of Accounts Concept

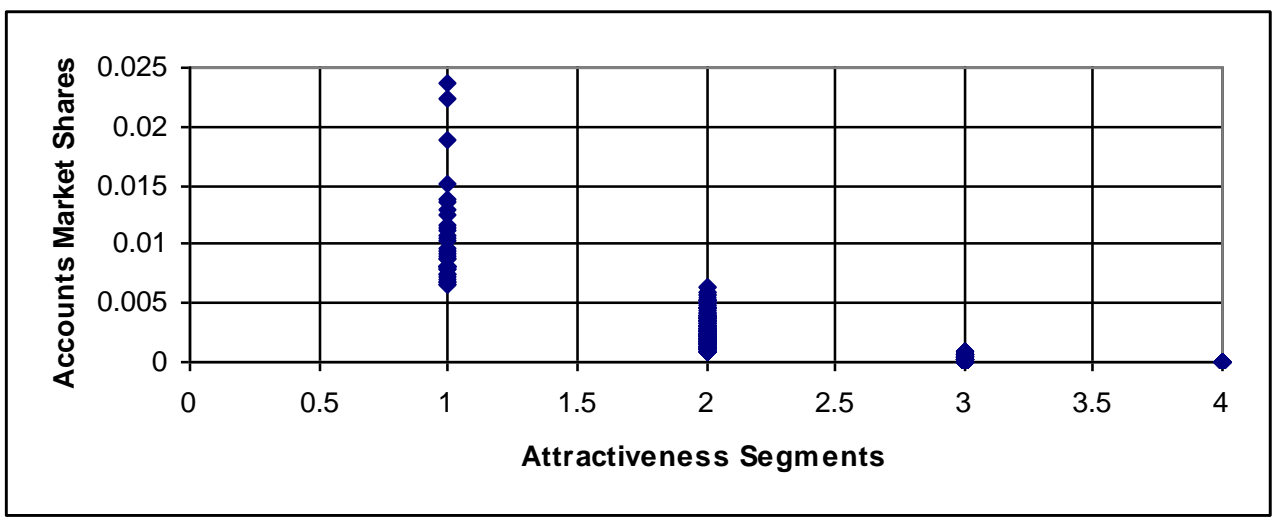


When the values for account's attractiveness have the call frequencies calculated, as shown in Table 5 below, it is clear that the salesforce strategy was quite good for Segment 2 and 3. Segment 2's strategy (with B accounts as the planning surrogate) was to call on those accounts at the rate of eight times per year, and an actual call frequency of 7.5 or $94 \%$ effectiveness was achieved. Similarly, Segments 1,3 and 4 were $79 \%, 91 \%$ and $16 \%$ effective. Notice that some accounts were under and some were over covered. The impact on the brand market shares will be quantified and the effects will be explored in the discussion section of this paper. Since the two biggest segments are 2 and 3, the strategy could be considered to be quite effective. However if the analysis did not use the multiplication approach, as illustrated by the more erratic dispersion seen in Table 4, the call frequency ratings provided in Table 5 clearly shows an entirely different diagnostic picture.

Table 5: Call Frequencies of Perfect Knowledge Benchmarked Compared to Portfolio Midpoint

\begin{tabular}{||c|c|c|c|c|c||}
\hline $\begin{array}{c}\text { Attract } \\
\text { Iveness } \\
\text { Segments }\end{array}$ & $\begin{array}{c}\text { Responders } \\
\text { Perfect-Knowledge }\end{array}$ & $\begin{array}{c}\text { Responders } \\
\text { Portfolio } \\
\text { Midpoint }\end{array}$ & $\begin{array}{c}\text { Mean Call Rate } \\
\text { Of Perfect- } \\
\text { Knowledge }\end{array}$ & $\begin{array}{c}\text { Mean Call Rate } \\
\text { Of Portfolio }\end{array}$ & $\begin{array}{c}\text { Strategy Sales } \\
\text { Call Effort }\end{array}$ \\
\hline 1 & 35 & 86 & 9.5 & 8.2 & 12.0 \\
\hline 2 & 202 & 26 & 7.5 & 8.2 & 8.0 \\
\hline 3 & 219 & 165 & 6.6 & 7.0 & 6.0 \\
\hline 4 & 15 & 194 & 6.2 & 6.8 & 1.0 \\
\hline
\end{tabular}

The results of Table 5 for the portfolio midpoint model show that the DogCare would have evaluated its success in the different segments according to lower success rates on every level except Segment 2 - 68\%, $98 \%$, $86 \%$ and $15 \%$ - for Segments 1 through 4 respectively. The results for the perfect-knowledge benchmark clearly shows the superior diagnostic insights gained from the comparison to the strategy and the additional robustness obtained from aligning the analysis with the implemented sales call strategy.

\section{Steps in Building an Attraction Model}

Based on the experience of this case history a more generalized attraction model can be induced. To derive this model the following major steps are required:

Start

Articulate Focused
Sales Call Strategy:
"What did the firm try
to accomplish in the
analyzed promotional
period?"

\section{End}

Compare Results
from Aligned to
Perfect Knowledge
scenarios: "How well
did the sales strategy
work?"

Figure 6: Six Key Steps for an Attraction Model
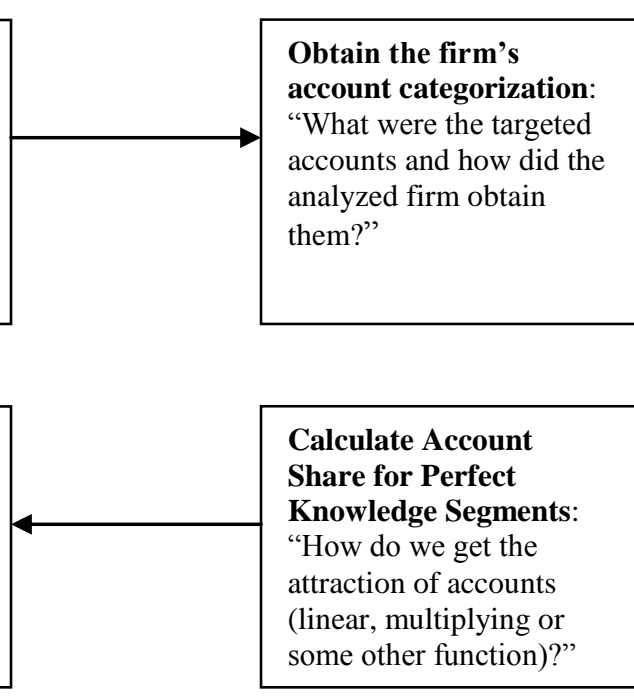

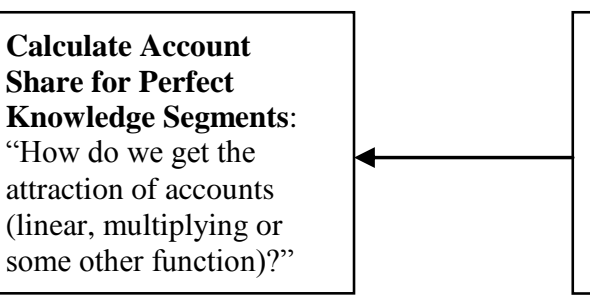

Calculate Account Share for Perfect Knowledge Segments: "How do we get the attraction of accounts some other function)?'

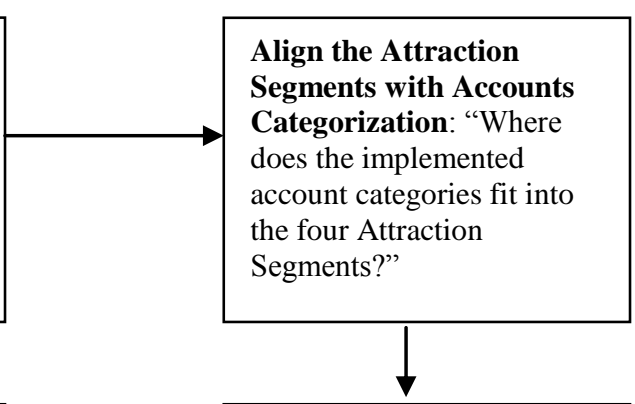

Operationalize the two Perfect Knowledge variables: "What must be measured to evaluate the sales call strategy?" 
The key step in these six steps is that the firm's strategy must be well understood, articulated and measurable. If it is focused, the operationalization of the variables will be meaningful. For example, if DogCare's strategy was to regain lost accounts from BestFriend, then the attraction segments would have been based on the multiplication of treatments per month and market share of BestFriend. The targets would then be BestFriend's key accounts. If market share retention or regaining market share is not the focused strategy, then the attraction variables need to be selected with the best measure that defines the attraction of the accounts to the firm based on its congruence to the sales effort strategy. Once the "perfect-knowledge" benchmark is set up, market research is conducted to obtain the data. The resulting evaluation can then be performed and presented to management.

One of the limitations of the portfolio analysis is the absence of a theoretical framework. This is not to depreciate the model's usefulness in salesforce training and profiling of accounts for planning a sales call strategy. However, as the analyses in this paper demonstrate, the use of the $\mathrm{X}$-Y coordinates with the two variables does not always lead to the best diagnostic insights. And it is not sufficient to say that one tool is for planning and the other tool is for post-hoc evaluation. A general theoretical framework needs to be found to handle both. On the other hand, the theoretical framework may already be present in the work of the decision models and instead of four quadrants we may be defining (albeit with greater complexity) a curve with continuous values as shown in Figure 5. The position of the segments can then be determined based on the number of calls that the salesforce budget will allow. In Figure 5, the Segments can then be defined at the accounts' cumulative positions of 35, 254, and 456. The first level gets 12 calls per year, the next eight calls, and so on. If this market share of accounts approach is appealing, a similar foundation has already been laid by BKL (1975) and needs only to be adapted in future research to apply to accounts.

Figure 5: Market Share of Accounts Curve

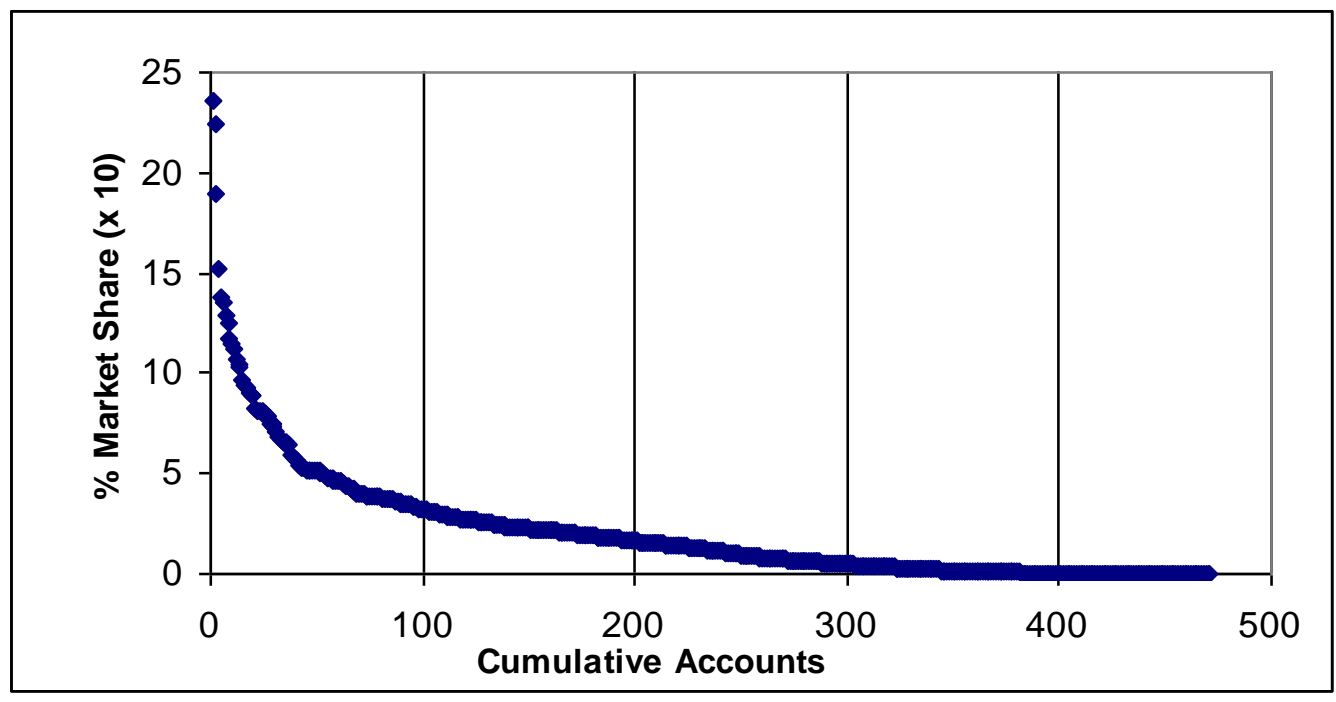

\section{Summary of the differences between Portfolio and Attraction Models}

The main differences between the two approaches are:

1. The portfolio model obtains the attractiveness segments using two X-Y axes. Values of the coordinates are then used to obtain a linear plot of the different accounts in a two dimensional space. The attraction model also uses two coordinates but they are, in DogCare's case, multiplied to obtain the value, which is then used to determine the attractiveness segment the account belongs to in the same accounts proportion as the implemented strategy. 
2. The two axes in the portfolio model are "account opportunity" and "strength of position" and are obtained from salesperson-administered questionnaire. The accounts are then placed into attractiveness segments for call effort decisions. However, the attraction model relies on salesforce or managerial judgments that have prioritized the accounts into essentially $\mathrm{ABCD}$ categories, which are then aligned to the salesforce strategy and positioned accordingly into attractiveness segments.

3. The portfolio model assumes that the ABCD categories are simplistic and incomplete. While this may be the case in some applications, the attractiveness model accepts them as a surrogate approach to defining attractiveness segments, not as simplistic but as a consequence of complex interplay of tacit knowledge and organizational learning of highly experienced salespeople.

4. The portfolio model leans towards being used to assign the accounts for the sales force effort and is in this role an a priori application. The attraction model is primarily a post-hoc analytical tool used primarily to evaluate implemented strategy but with the potential to be a planning tool and to make corrective recommendations.

5. The portfolio model is specific in its requirement of using linear account plots. However, the attraction model can handle any functional relationship of the two axes or variables - be they linear, multiplicative or some other function like exponential. Therefore, the attraction model is a more generalized model with portfolio as a special case.

6. The attraction model requires that the salesforce strategy of the analyzed firm be the focus of the operationalization of the variables and the correct source of the proportioning for the alignment of the accounts. It therefore has the intention of reflecting the budget allocation of resources and is intended to determine the effectiveness of these allocation decisions. The portfolio approach is more concerned with directing these resource allocations or recommending their improvement.

7. The portfolio model is more interested in defining attractiveness segments, while the attraction model is more consumed by finding the appropriate measure of the attraction of accounts of the analyzed firm for that particular strategy.

\section{Discussion and Managerial Implications}

Managerial judgments in salesforce deployment will always benefit from the availability of helpful models like the portfolio model. In many reported instances, the use of this model for planning sales call strategies and their evaluation has been, according to LaForge et al (1985), quite successful. However, the general portfolio model needed several modifications for the analyses of DogCare's sales strategy. The first and most important change was the recognition that the analyzed firm's strategy had to be used to align the axes for the model. Operationalization of the account opportunity and strength of position axes reflected the two focal points of the sales strategy: size of account and market share of DogCare's brand in those accounts. The sales strategy, as evident by the dispersion of the categorization of the accounts seen in Table 3, was that DogCare wanted to retain as many of its key accounts as possible. Therefore, the measurement of this strategy's success was to see how often these accounts were called on as the sales call policy prescribed. The second change was that in order to see how well this worked, the pairs of values for account opportunity and strength of position had to be multiplied to provide one data point rather than the two values used as X-Y coordinates. When a series of single values were obtained and used to define the four segments, a more powerful diagnostic tool was developed. Alternatively, the portfolio model approach provided more erratic diagnostic insights as was reported earlier in Table 4.

In our six-steps for building the attraction model, the recommendation to management was not included as the last step. However, strategic recommendations could have been made. One improvement that DogCare could make is to obtain a better identification system for their accounts. From the misclassification of the accounts, as shown in the Appendix in the last column, the proportion of misclassification maybe considered too high by management and a better method of classifying the accounts needs to be found. The misclassification proportion and the lost market share from over and under coverage can also be quantified. Note from Table 3 on page eight, that in the A categories there were only 14 that were really congruent with the actual data and 23 were under-called. For the B accounts, 131 were correctly covered, 20 were over-called and 68 were under-called. For the $\mathrm{C}$ accounts, 115 were correctly covered 77 were over-called and 10 were under-called. D was virtually totally misclassified. Using this data, Table 6 shows the impact of this misclassification: 
Table 6: Gain/Loss Market Share of Misclassified Accounts

\begin{tabular}{||c|c|c|c||}
\hline Coverage Differences & Accounts & Mean & Std. Dev. \\
\hline Correctly Covered & 261 & $60.4 \%$ & 37.3 \\
\hline Over-Covered & 90 & $74.6 \%$ & 32.9 \\
\hline Under-Covered & 120 & $46.8 \%$ & 45.7 \\
\hline Overall Market Share & 471 & $59.6 \%$ & 39.8 \\
\hline
\end{tabular}

The above results show the extent of the over and under coverage and the impact on market share. Note that overall impact on these is a decrease of only 0.8\% (Overall Market Share of 59.6\% less 60.4\% for Correctly Covered) because the over and under covered has an offsetting and canceling effect. Since this is a zero-sum game, the best market share position for DogCare could only be as good as the value for correctly covered, even if the 90 over-covered and 120 under-covered were correct. The wastage of coverage of $0.8 \%$ market share doesn't seem large, but it is still equivalent to $\$ 2.5$ million in revenue-more than enough profit at $50 \%$ margin to find an improved classification scheme.

Managers and researchers alike need to be mindful of the model's strengths and limitations. For example, the portfolio model assumes that the $\mathrm{ABCD}$ rating of accounts, as representing the simplified approach is only intended as a measure of account opportunity. However, as seen in the way DogCare defines the ABCD categories, they represented a subjectively defined targets list that took into consideration the thrust of both axes and not just the account opportunity axis. In effect, the ABCD categorization represented DogCare's best judgment on which accounts to call on and with what frequency level. As several well known researchers have observed when researching this area "experience and wisdom are sometimes better than models" (Sinha and Zoltners, 2001). It should also be kept in mind that some of the sales people have managed their territories for over 15 years and this accumulated organizational learning and tacit knowledge is a valuable resource. In the examples provided in this paper, the judgment of the sales and marketing management was quite adept at targeting to their key accounts. Moreover, the success can be seen in the slowing to a plateau the loss of market share so that by the end of 1999, the date of this analysis, DogCare has stabilized its market share to $42 \%$, the same value as the previous year after many years of large decreases. The managerial implication of this is a reinforcement of the judgmental approach. Yet at the same time, this paper recommends that there is a need for a post-hoc analysis to evaluate if the organization can really trust its judgmental decisions. This would be a prudent step since there is heavy reliance on managerial judgments for a successful salesforce deployment.

Even with the wisdom of this kind of post-hoc analysis, the future of sales management will continue to benefit from the improved salesforce automation and more prevalent use of mathematical decision models. Although the issue of how to procure all the data required reliably will remain an obstacle for many of the salesforces in industrial markets, the power of the laptop in the hands of the salesforce must be harnessed if competitive advantages are to be sustained. The calculation of the appropriate call frequency for an account is the main attribute of the variety of alignment software packages that are now commonly available. These include territory alignment software such as MAPS ${ }^{\mathrm{TM}}$ (ZS Associates), TerrAlign (Metron), ProAlign (MapInfo Corporation) and several others. The approach of these packages solves the deficiencies of a system, like DogCare's, that assigns similar call frequencies for group of accounts and therefore suffers from sub-optimal account coverage. While the use of call frequency calculating packages may be an improvement, this more flexible approach does present management with control issues. Care needs to be exercised in balancing the benefit of more and better targeting sales effort data with the salesforce need for clear and unambiguous direction. Moreover, the buy-in on the use of complex algorithms, as has been mentioned earlier, has the potential to lead to rejection or even non-use of these productivity aids.

\section{References}

1. Bell, David E., Ralph L. Keeney \& John D. C. Little, John D. C. [1975], “A Market share Theorem,” Journal of Marketing Research, XII (May), 136-41. 
2. Bonoma, Thomas V. (1985), "Case Research in Marketing: Opportunities, Problems, and a Process", Journal of Marketing Research, XXII, 199-208.

3. David W. Cravens (1979), "Salesforce Decision Models: A Comparative Assessment," Sales Management: New Developments from Behavioral and Decision Model Research, ed. R. P. Bagozzi (Cambridge, Mass: Marketing Science Institute), 310-324.

4. Easingwood, C. (1973), "Heuristic Approach to Selecting Sales Regions and Territories," Operations Research Quarterly, December 527-534.

5. LaForge, Raymond W, David W. Cravens, and Clifford E. Young (1985), "Improving Salesforce Productivity", Business Horizon, September-October, 50-59.

6. Leonard M. Lodish (1971), "CALLPLAN: An Interactive salesman's call planning system," Management Science, Vol. 18, No. 4, Part 2 (December), 25-40.

$7 . \quad$ January/February: p.119-124.

8. $\quad$----------- (1975), "Sales Territory Alignment to Maximize Profit", Journal of Marketing Research, February 30-36.

9. Heide, Christen P. (1998-1999), Dartnell's $30^{\text {th }}$ Sales Force Compensation Survey, Chicago: Dartnell Corporation.

10. Heschel, Michael S. (1977), “Effective Sales Territory Development.” Journal of Marketing, April 39-43.

11. Hess, Sidney W. and Stuart A. Samuels (1971), "Experiences with a Sales Districting Sales Districting Model: Criteria and Implementation." Management Science, December, 41-54.

12. Richardson, Robert J. (1979), "A Territory Realignment Model-MAPSTM", Presented at the New Orleans ORSA/TIMS meeting, May 1.

13. Segal, M. and D.B. Weinberger (1977), “Turfing”, Operations Research, May-June, 367-386.

14. Skiera, Bernd and Sonke Albers (1996), "COSTA: Contributions Optimizing Sales Territory Alignment," Working Paper at Christian-Albrechts-Universitat zu Kiel, Germany, October, revised August 1977.

15. Sinha, Prabhakant, and Andris A Zoltners (2001), "Sales-force decision models: Insights from 25 years of implementation", Interfaces, Vol. 31, Issue 3, S8-S44.

16. Zoltners, Andris A, and Sally E. Lorimer (2000), "Sales Territory Alignment: An Overlooked Productivity Tool", Journal of Personal Selling \& Sales Management, Vol. XX, No. 3, Summer, 139-150.

17. (1999), "Sales Force Management Program-Trivia Contest," Executive Education Program, J.L. Kellogg Graduate School of Management, Northwestern University.

18. ( and Prabha Sinha (1983), "Sales Territory Alignment: A Review and Model," Management Science, November, 1237.

Notes

APPENDIX A: EXAMPLE OF DATA SET

\begin{tabular}{|c|c|c|c|c|c|c|c|c|c|c|c|c|}
\hline Clinic & $\begin{array}{l}\text { Sum } \\
\text { Of } \\
\text { Total }\end{array}$ & $\begin{array}{c}\text { Account } \\
\text { Opportunity }\end{array}$ & $\begin{array}{l}\text { Strength Of } \\
\text { Position }\end{array}$ & $\begin{array}{c}\text { Portfolio } \\
\text { Midpoint } \\
\text { Segment }\end{array}$ & $\begin{array}{l}\text { Market Share } \\
\text { Of Dogcare }\end{array}$ & $\begin{array}{c}\text { Attraction } \\
\text { Model-Perfect } \\
\text { Knowledge }\end{array}$ & \begin{tabular}{|c|} 
Sum \\
Of \\
Dogcare \\
Treatments Per \\
Month
\end{tabular} & $\begin{array}{l}\text { Accounts } \\
\text { Share Of } \\
\text { Dogcare }\end{array}$ & $\begin{array}{c}\text { Classifications } \\
\text { Of } \\
\text { Accounts Of } \\
\text { Dogcare }\end{array}$ & $\begin{array}{l}\text { Sales Calls } \\
\text { Frequency }\end{array}$ & Aligned & $\begin{array}{r}\text { Miscla } \\
\text { Acco }\end{array}$ \\
\hline
\end{tabular}


International Business \& Economics Research Journal

\begin{tabular}{|c|c|c|c|c|c|c|c|c|c|c|c|c|}
\hline & & Intern & ust & con & Pesea & na & & & lun & $m b c$ & & \\
\hline 23853 & 15744 & 1 & 1 & 1 & 100 & 1 & 15744 & .0107349 & $B$ & 8 & 2 & $\bar{\tau}$ \\
\hline 22518 & 666 & 2 & 1 & 3 & 100 & 3 & 666 & .0004541 & $\mathrm{C}$ & 6 & 3 & $c$ \\
\hline 7378 & 13866 & 1 & 1 & 1 & 100 & 1 & 13866 & .0094544 & $\mathrm{~A}$ & 12 & 1 & $c$ \\
\hline 327 & 12966 & 1 & 1 & 1 & 100 & 1 & 12966 & .0088407 & $\mathrm{~B}$ & 8 & 2 & $\mathrm{U}$ \\
\hline 6451 & 10884 & 1 & 1 & 1 & 100 & 1 & 10884 & .0074211 & B & 8 & 2 & $\mathrm{U}$ \\
\hline 6947 & 4161 & 2 & 1 & 3 & 100 & 2 & 4161 & .0028371 & $C$ & 6 & 3 & $\tau$ \\
\hline 13328 & 3900 & 2 & 1 & 3 & 100 & 2 & 3900 & .0026592 & $\mathrm{C}$ & 6 & 3 & $\mathrm{U}$ \\
\hline 13469 & 3684 & 2 & 1 & 3 & 100 & 2 & 3684 & .0025119 & $\mathrm{~B}$ & 8 & 2 & $c$ \\
\hline 11377 & 3528 & 2 & 1 & 3 & 100 & 2 & 3528 & .0024055 & B & 8 & 2 & $c$ \\
\hline 5177 & 3474 & 2 & 1 & 3 & 100 & 2 & 3474 & .0023687 & B & 8 & 2 & 0 \\
\hline 8973 & 3456 & 2 & 1 & 3 & 100 & 2 & 3456 & .0023564 & C & 6 & 3 & t \\
\hline 14862 & 3228 & 2 & 1 & 3 & 100 & 2 & 3228 & .0022010 & B & 8 & 2 & c \\
\hline 6568 & 3186 & 2 & 1 & 3 & 100 & 2 & 3186 & .0021723 & C & 6 & 3 & U \\
\hline 17680 & 3162 & 2 & 1 & 3 & 100 & 2 & 3162 & .0021560 & B & 8 & 2 & $c$ \\
\hline 13064 & 3132 & 2 & 1 & 3 & 100 & 2 & 3132 & .0021355 & C & 6 & 3 & U \\
\hline 23194 & 3126 & 2 & 1 & 3 & 100 & 2 & 3126 & .0021314 & $\mathrm{C}$ & 6 & 3 & $\mathrm{c}$ \\
\hline 25331 & 1050 & 2 & 1 & 3 & 100 & 3 & 1050 & .0007159 & $\mathrm{C}$ & 6 & 3 & $c$ \\
\hline 11104 & 1038 & 2 & 1 & 3 & 100 & 3 & 1038 & .0007077 & $\mathrm{~B}$ & 8 & 2 & 0 \\
\hline 10155 & 954 & 2 & 1 & 3 & 100 & 3 & 954 & .0006505 & $\mathrm{C}$ & 6 & 3 & $\mathrm{c}$ \\
\hline 8212 & 942 & 2 & 1 & 3 & 100 & 3 & 942 & .0006423 & $\mathrm{C}$ & 6 & 3 & $c$ \\
\hline 22052 & 900 & 2 & 1 & 3 & 100 & 3 & 900 & .0006137 & B & 8 & 2 & $c$ \\
\hline 12608 & 822 & 2 & 1 & 3 & 100 & 3 & 822 & .0005605 & B & 8 & 2 & $c$ \\
\hline 23476 & 816 & 2 & 1 & 3 & 100 & 3 & 816 & .0005564 & $\mathrm{C}$ & 6 & 3 & $c$ \\
\hline 25036 & 816 & 2 & 1 & 3 & 100 & 3 & 816 & .0005564 & C & 6 & 3 & $c$ \\
\hline 879 & 702 & 2 & 1 & 3 & 100 & 3 & 702 & .0004787 & C & 6 & 3 & $\mathrm{c}$ \\
\hline 22518 & 666 & 2 & 1 & 3 & 100 & 3 & 666 & .0004541 & $\mathrm{C}$ & 6 & 3 & $c$ \\
\hline
\end{tabular}


Notes 